\title{
Geo-Referenced Procedure to Estimate the Urban Energy Demand Profiles Towards Smart Energy District Scenarios
}

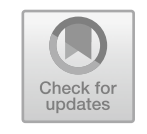

\author{
Simone Ferrari, Federica Zagarella and Paola Caputo
}

\begin{abstract}
To effectively reduce cities' environmental impact, current policies boost building stocks transition towards smart energy systems (i.e. distributed energy generation, renewables integration, energy storage, connection to district heating and cooling networks). Smart energy systems feature complex-related energy fluctuations, since they include the intermittent and unpredictable behaviour of renewable energies and the variable energy demand of buildings. However, the technical literature underlines the need for accurate methods adoptable in several urban contexts for detailed energy demand assessment. In this framework, a method to estimate the energy demand profiles of urban buildings has been developed with particular regard to the Italian contexts. The method includes a geo-referenced procedure to assess the volumetric consistency of a building stock by age, characterizing different technological solutions, and by the mostly diffuse urban use categories, i.e. residential and common tertiary (office), affecting different usage profiles, thanks to data available for the national territory. Specifically, spatial datasets on buildings from the Topographic Database, currently under standardization based on the European (INSPIRE) directive, and from the National Institution of Statistics (Istat) were used. In order to determine current hourly energy profiles, a set of dynamic energy simulations is foreseen, based on simplified reference buildings. Hence, the energy behaviour of selected building portions, representative of different heat exchanges boundary conditions, can be assessed. The derived hourly energy profiles per built volume can, therefore, be consistently associated with the considered building stock to obtain the overall hourly energy demand. Moreover, by assigning the upgraded technological properties to the reference buildings, it is possible to replicate the procedure and derive the variation of energy profiles for the defined retrofit scenario. The method has been tested on the city of Milan and is validated on a yearly basis.
\end{abstract}

S. Ferrari $(\varangle) \cdot$ F. Zagarella $\cdot$ P. Caputo

Architecture, Built Environment and Construction Engineering-ABC Department, Politecnico di Milano, Milan, Italy

e-mail: simone.ferrari@polimi.it 
Keywords Smart energy district planning - Geographic information system (GIS) • Building stock geodatabase • Urban energy profiles estimation • Topographic database $\cdot$ National institution of statistics (Istat) census

\section{Introduction}

The recently issued Agenda 2030 included the improvement of the energy sector and cities as goals to achieve global sustainable development (UN 2015). In fact, cities are responsible for 70\% in the global energy demand (UNEP 2015), which is expected to increase in step with urban population. Hence, given the opportunity for a further exploitation of fossil resources, substantial changes in the energy production mix, largely integrating renewable energy sources (RES), are promoted by worldwide policies.

Italy is currently one of the lowest energy intensity European countries, having boosted in past decade the adoption of energy efficiency measures and the integration of RES with mandatory requirements and considerable tax subsidies. In spite of this, its energy mix is not one of the most RES based in the European Union (EU), despite its large potential. Therefore, within the National Energy Strategy (MiSE 2017), a large increment of RES share and a reduction in final energy consumption is predicted, thanks to several indicated actions, e.g. distributed energy generation, replacement in buildings of conventional systems with heat pumps and biomass ones, installation of photovoltaic panels on buildings surfaces, district heating and cooling networks in densely populated areas, demand response programmes, energy storage at building and district levels.

On a broader scale, the transition of urban areas towards Smart Energy Districts implies a quite complex management of the mismatch between energy demand and supply. In fact, the renewable energy availability is quite unpredictable and variable both on daily and annual bases. Moreover, the demand side is variable, considering an existing plenty of different uses and the increasing role of active consumers. To properly manage these energy systems, by minimizing the related inefficiencies and costs, an accurate knowledge of their dynamic behaviour is fundamental.

Indeed, for supporting urban energy planners in this task, several different computational tools have been developed. Focusing on tools for smart energy planning on an urban/districts scale, the more detailed ones require the hourly based profiles of energy demand to be inserted for the studied context (Ferrari et al. 2019a). At the same time, having detailed energy profiles is a challenging task, since the availability of actual energy profiles for any context is not widespread (Fig. 1). In technical literature, this has led either to adopting approximate energy data, which could not be adequate for this purpose, or to defining robust estimation methods, which usually refer to 'engineering' and 'statistical' categories and the choice of which can be driven by the level of detail of held and desired data (Ferrari et al. 2019a, b).

With this in mind, within a Ph.D. research at the ABC Department (Zagarella 2019), a method has been defined for the accurate estimation of the energy demand 


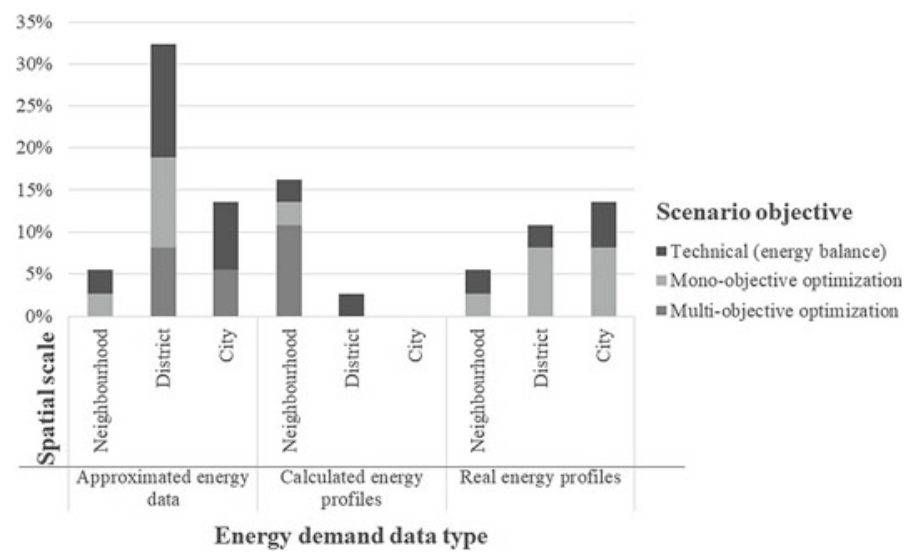

Fig. 1 Surveyed studies by spatial scale, energy scenario objective and type of energy demand data

profiles of an existing building stock, with reference to spatial data largely available from public administration across the Italian territory.

\section{Digitized Spatial Data on the Built Environment}

The EU highlighted the relevance of data availability to boost environmental policies as well as their ease of access, harmonisation and interoperability. Thus, with the Directive 2007/2/EC, the EU established general rules for the Infrastructure for Spatial Information in the European Community (INSPIRE). In Italy, the digitization process of public data had already begun back in 2005 (D.Lgs. 82/2005) but carried out only a limited number of concrete initiatives (Pasquinelli and Guzzetti 2006). In 2010, the INSPIRE Directive was implemented with the D.Lgs. 32/2010. From the national inventory of spatial data (Repertorio Nazionale dei Dati Territoriali or RNDT), which collects spatial metadata available at public administrations, a plenty of different types of data emerges with regards to the built environment (Fig. 2), although not all of it is uniformly collected and diffused across the territory.

Among the potentially available spatial datasets on buildings, a fundamental one is the so-called Topographic Database (TDb), introduced by the D.M. 10/11/2011 and currently under standardization to European (INSPIRE) and National (Intesa GIS) specifications. The TDb is made up of geo-referenced and updatable data, hierarchically structured into 'Layers', 'Themes' and 'Classes'. The latter are the mandatory basic unit of a TDb and comprise geometries associated with tabular data. Within the Layer 'Real estate and human settlements' and the Theme 'Built Environment', the following Classes are foreseen: the 'Building', the 'Volumetric Unit' (a building portion with same height), the 'Building Group' (a sum of buildings 


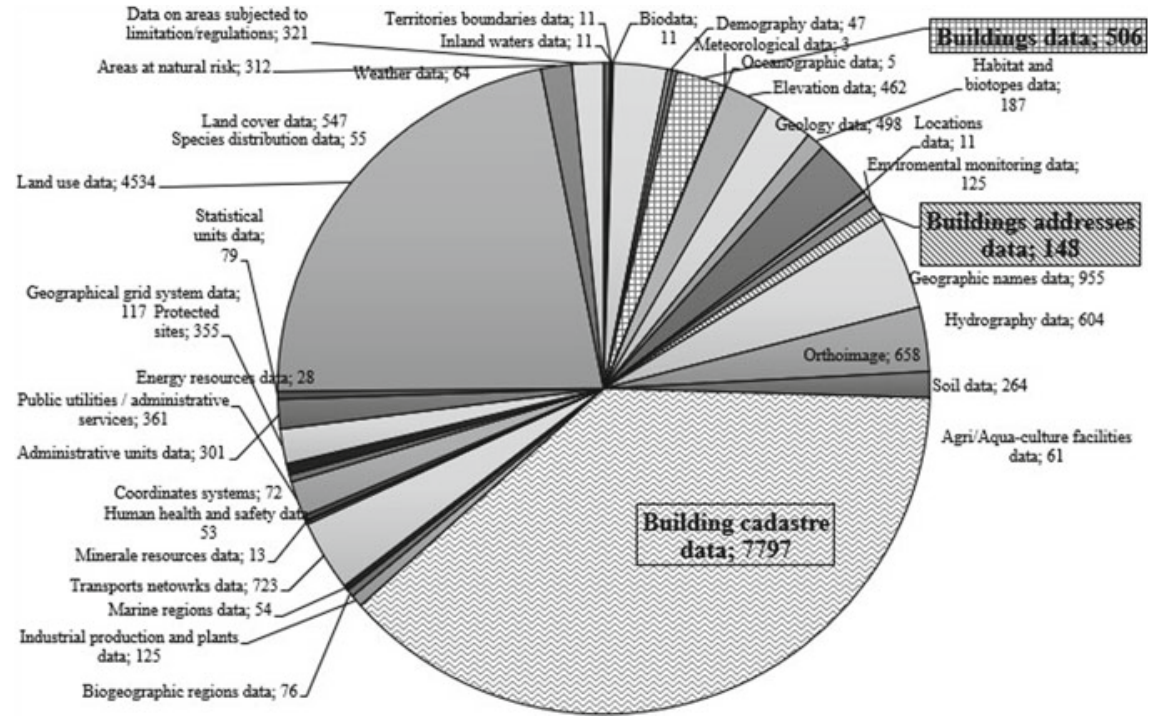

Fig. 2 Digitized spatial datasets classified by INSPIRE theme reported in the RNDT

having only external walls), the 'Roof Element', the 'Architectural Detail', and the 'Minor Building' (unstable volume attached to a building).

Another well-known and proved database of spatial data on buildings in Italy is the one coming from the 15th General Census of Population and Houses (GCPH), charged to the National Institution of Statistics, (Istat 2011). Since 2001 the 10 years census has been made of the population survey, which is carried out by means of questionnaires filled by respondents, and the survey on the existing buildings, carried out on-site by Istat technicians. Regarding the former, data was collected through a short form, given to most people and including the minimum set of data required by the European Statistical Office, and a longer form, sent to a sample of people. ${ }^{1}$ Information from the longer form could be truly interesting for modelling energy use of the built environment (e.g. installed systems for space heating, space cooling, DHW energy and RES-based systems for electricity) although their access is quite restricted.

Public data was disseminated for defined spatial units (e.g. Census Unit, ${ }^{2}$ Census Area, ${ }^{3}$ etc.) by means of two datasets: the 'Spatial Bases', which only consist of

\footnotetext{
${ }^{1}$ In cities with less than 20 thousand inhabitants on 1 January 2008, the sample corresponds to the whole residing population; in cities with a population above the set threshold and in chief towns it corresponds to one-third of the people, selected among the so-called Census Areas.

${ }^{2}$ The Census Unit is the smallest urban area containing groups of buildings.

${ }^{3}$ The Census Area is a group of contiguous Census Units, with a population of 13-18 thousand the boundary of which was defined based on administrative divisions, infrastructures and natural elements.
} 
the geographic representation of the statistical units, and the 'Statistical Variables', which contain a selection of data on population, dwellings and buildings.

\section{Methodology}

A method has been defined for supporting bodies involved in the energy planning at urban/district level. As hereinafter described, it has been intended to provide a method that can be both easily updated, in order to consider building energy retrofit scenarios as well, and widespread adopted, thanks to largely available spatial data. In detail, a geodatabase of an urban building stock, characterized by related energy features, is implemented in a Geographic Information System (GIS), namely in the QGIS tool with the embedded Python console (Fig. 3).

Buildings stock characterization was driven by the following considerations: the buildings' energy demand is largely influenced by building geometry, technological solutions and usage profiles, hence a procedure to calculate the building stock volume, differed by mostly diffuse urban use categories, i.e. residential and common tertiary (office), construction periods (i.e. from old traditional buildings to recent buildings complying with energy-saving requirements) and different portions of buildings, i.e. referring to different heat exchange boundary conditions (thermal zones) was defined.

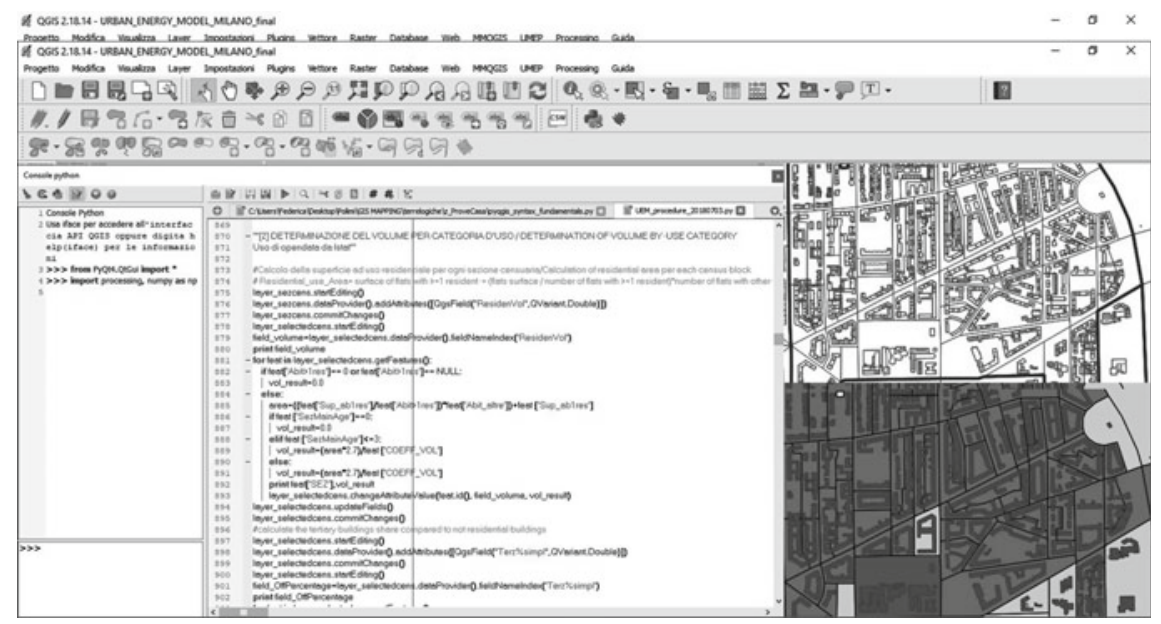

Fig. 3 QGIS tool with Python console embedded 
First, a construction period for all buildings included in each Census Unit is determined taking into account the relative consistency in terms of building units, ${ }^{4}$ which leads to the buildings' volume magnitude, based on the data reported in the GCPH.

Second, the characterization of buildings by thermal zones has been accomplished by prior calculation of the built volume based on TDb geometric data and its adjustment for accounting for only conditioned volumes (i.e. excluding staircases, small service volumes, etc.) and by grouping contiguous Volumetric Units (i.e. for considering only external walls in assessing the heat exchanges of the buildings' volumes). Then, for a previously defined simplified building energy model (Ferrari and Zagarella 2016), different thermal zones were classified with reference to the main boundary conditions of heat exchange: the ones placed on the intermediate storey (i.e. floors do not exchange heat), the ones on the first conditioned storey (i.e. floor exchanging heat with the unconditioned basement) and the ones on the last conditioned storey (i.e. ceiling bordering the sky). For each storey, thermal zones were additionally classified into the ones in angular positions (i.e. with two vertical walls towards outside) and the ones in intermediate positions (i.e. with just one external wall). Hence, the resulting six thermal zones of the simplified building model (Fig. 4) are consistently associated with the buildings of the considered stock.

Third, to characterize the building stock by use category, for each Census Unit, the total residential built volume is calculated based on the overall residential building units' number and floor surface data from the GCPH. Then, the not-residential volume is deduced from the total built volume minus the residential one; from the former, the common tertiary (office) volume is, in turn, deduced proportionally to the related office buildings number (data coming from the GCPH).

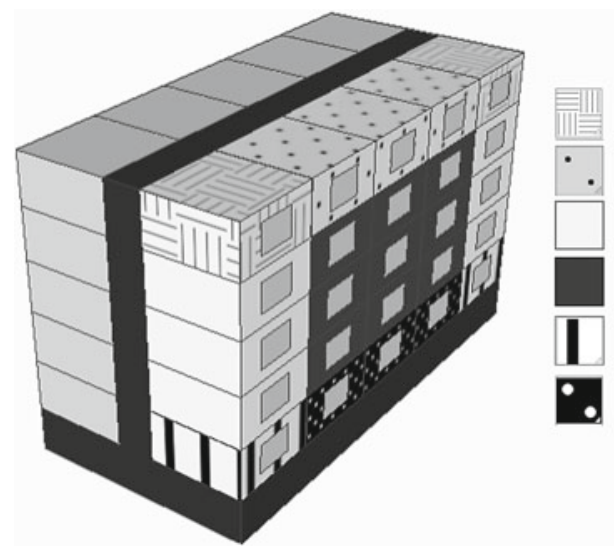

Top floor - corner position (TC)

Top floor - intermediate position (TI)

Intermediate floors - corner position (IC)

Intermediate floors - intermediate position (II)

Ground floor - corner position (GC)

Ground floor - intermediate position (GI)

Fig. 4 Simplified building energy model and classification of thermal zones

\footnotetext{
${ }^{4} \mathrm{~A}$ building unit is either defined as a real estate unit (residential, office, commercial, etc.) accessed from a building collective distribution area or a residential estate unit accessed from outside and with its own address.
} 


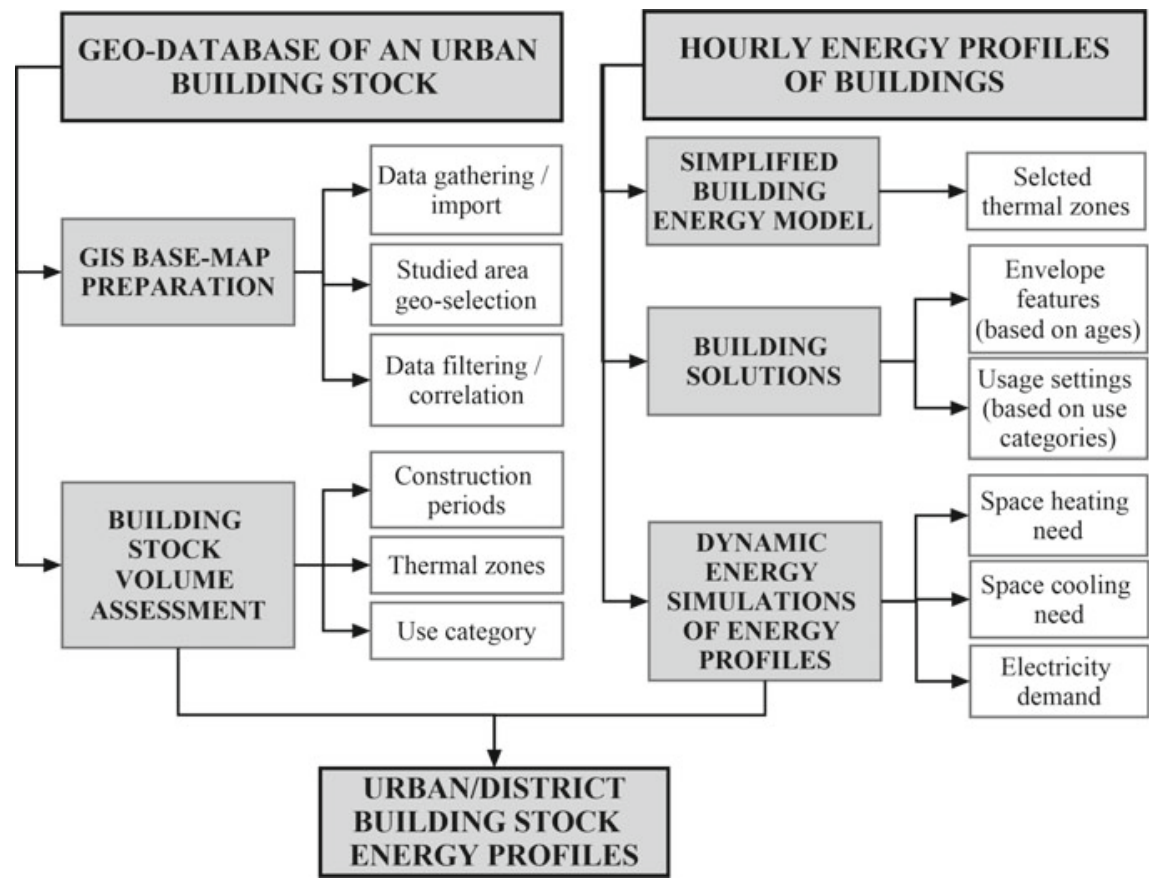

Fig. 5 Flowchart of the defined method

Once this is carried out, based on a set of alternative inputs for characterizing the building energy model into different building solutions, defined for covering the main construction periods and use categories, the hourly based energy profiles of space heating, space cooling and electricity for the selected thermal zones can be obtained through dynamic energy simulations.

Finally, the resulting energy profiles can be associated with the considered building stock volume to obtain the overall urban/district area energy profiles.

Figure 5 outlines the details of the defined method.

\section{Case Study Application}

The defined method to obtain the buildings' energy demand profiles was tested in the city of Milan. First, the building stock has been characterized by construction periods, thermal zones and use categories according to the GIS-based procedure. From results visualized in Fig. 6, it can be noted that in the city centre most of buildings are old, large (prevalence of intermediate thermal zones) and for office use, and vice versa in the outskirts as is what happens in reality. 


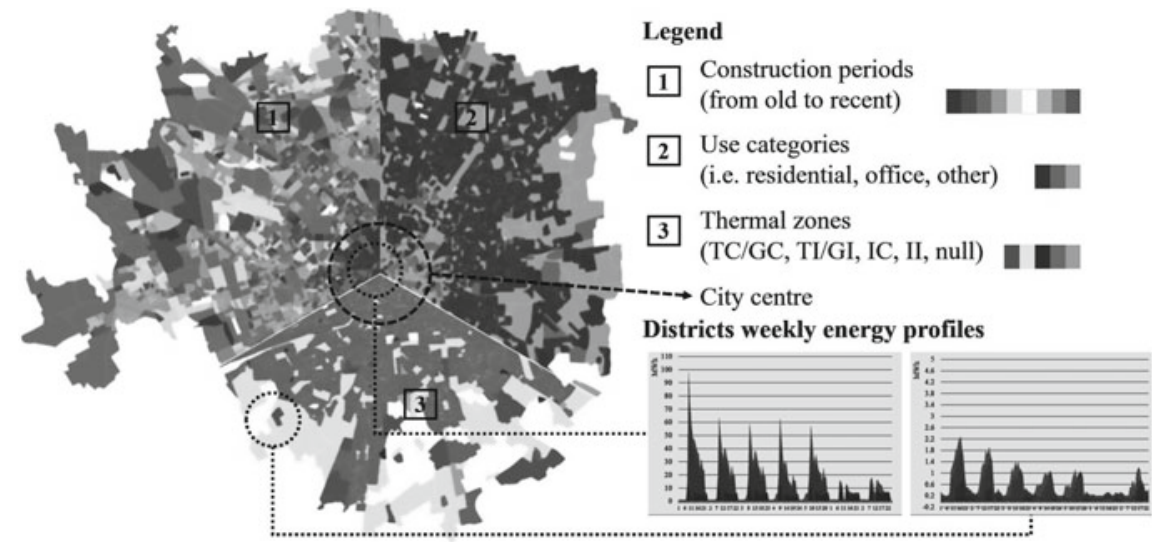

Fig. 6 Visualization of characterized building stock and district energy profiles for the case study

Once the urban building stock is characterized, a set of buildings energy solutions was alternatively associated with the simplified building energy model, by adopting different envelope characteristics based on age (Ferrari and Zanotto 2016a) and internal heat loads and air change rate profiles depending on the use categories (ISO 17772:2017).

The space heating activation period was set based on the D.P.R. 412/1993 and, according to (Ferrari and Zanotto 2016b), in residential cases, both the adoption of the adaptive approach for the set-point temperatures and a free cooling strategy for ventilation were considered during non-heating season. Hence, by means of dynamic energy simulations with TRNSYS (Klein et al. 2014), the energy profiles of space heating and cooling needs and of electricity demand were determined and converted into profiles of energy per built volume. These last ones have been associated with the considered built volume in GIS (an example of results for two districts is reported in Fig. 6).

Finally, due to a current lack in measured urban energy profiles, the energy demand calculated for the case study were validated on a yearly base, by comparing the results obtained for the overall residential building stock with the yearly urban residential energy consumptions derived from the regional energy balance (SIRENA 2012), assuming typical thermal systems' seasonal efficiencies from (UNI/TS 11300:2014 and D.M. 26/6/2015), and the energy consumption for Domestic Hot Water from (Ferrari and Zagarella 2015). ${ }^{5}$

Conversely, since tertiary buildings are usually equipped with quite complex HVAC systems, a reliable estimation of their energy performance, to be validated with yearly based registered consumption, will be possible only in further research development.

\footnotetext{
${ }^{5}$ Since tertiary buildings are usually equipped with quite complex HVAC systems, a reliable estimation of their energy performance, to be validated with yearly based registered consumption, will be possible only in further research development.
} 


\section{Conclusions}

The assessment of hourly energy demand of the existing building stock, as well as the prediction of its variation due to energy efficiency measures, are fundamental activities for planning strategies of distributed energy generation, district heating and/or cooling networks, renewables integration, energy storage, etc., towards smart energy districts.

To support bodies in planning smart energy scenarios at urban/district level, a method has been defined to estimate the energy demand profiles of urban buildings. The method, which includes dynamic energy simulations of alternative solutions assigned to a simplified reference building model, foresees a GIS-based procedure useful to characterize the considered built volume by age, implying different technological solutions, and by the mostly diffuse urban use categories, i.e. residential and common tertiary (office), affecting different usage profiles. This procedure is based on spatial datasets which are widely available across the national territory (i.e. the Topographic Database, currently under standardization according to the INSPIRE directive, and the Istat population and houses census).

The method was applied to the case study of Milan building stock and accomplished elaborations produced valid results, as compared with available yearly based statistical energy data (i.e. the regional energy balance SIRENA).

The defined method is also suitable to assess the variation of the energy demand profiles due to buildings retrofit policies. In fact, by assigning the upgraded technological properties to the reference buildings, it is possible to replicate the procedure and derive the building stock profiles of the defined retrofit scenario.

Acknowledgements The authors thank the Annex 75 "Cost-effective Building Renovation at District Level Combining Energy Efficiency \& Renewables" working group of the International Energy Agency - Energy in Buildings and Communities Programme - for having stimulated some deepenings of the present research.

\section{References}

D.Lgs. 27 gennaio 2010, n. 32. Attuazione della direttiva 2007/2/CE, che istituisce un'infrastruttura per l'informazione territoriale nella Comunità europea (INSPIRE), Rome (in Italian)

D.Lgs. 7 marzo 2005, n. 82. Codice dell' amministrazione digitale, Rome (in Italian)

D.P.R. n. 412/1993, Regolamento recante norme per la progettazione, l'installazione e la manutenzione degli impianti termici degli edifici, ai fini del contenimento dei consumi di energia, in attuazione dell'art. 4, comma 4 della legge 9 gennaio 1991, n. 10. (aggiornata dal D.P.R.551/99) (in Italian)

Ente Nazionale Italiano di Unificazione (UNI). UNI/TS 11300-2:2014. Prestazioni energetiche degli edifici Parte 2: Determinazione del fabbisogno di energia primaria e dei rendimenti per la climatizzazione invernale, per la produzione di acqua calda sanitaria, per la ventilazione e per l'illuminazione in edifici non residenziali 
EU (2007) Directive 2007/2/EC of the European Parliament and of the Council of 14 March 2007 establishing an Infrastructure for Spatial Information in the European Community (INSPIRE), Brussels

Ferrari S, Zagarella F (2015) Costs assessment for building renovation cost-optimal analysis. Energy Proc 78:2378-2384

Ferrari S, Zagarella F (2016) Assessing buildings hourly energy needs for urban energy planning in southern European context. Proc Eng 161:783-791

Ferrari S, Zagarella F, Caputo P, Bonomolo M (2019a) Assessment of tools for urban energy planning. Energy 176:544-551

Ferrari S, Zagarella F, Caputo P, D’Amico A (2019b) Results of a literature review on methods for estimating buildings energy demand at district level. Energy 175:1130-1137

Ferrari S, Zanotto V (2016a) Defining representative building energy models. In: Building energy performance assessment in southern Europe, SpringerBriefs in Applied Sciences and Technology, pp 61-77

Ferrari S, Zanotto V (2016b) Energy performance analysis of typical buildings. In: Building energy performance assessment in southern Europe. SpringerBriefs in Applied Sciences and Technology, pp 79-98

International Organization for Standardization (ISO). ISO 17772-1:2017. Energy performance of buildings-Indoor environmental quality-Part 1: indoor environmental input parameters for the design and assessment of energy performance of buildings

Intesa Stato Regioni Enti Locali Sistemi Informativi Territoriali. Specifiche per la Realizzazione dei Database Topografici di Interesse Generale-Il catalogo degli oggetti-Revisione delle Specifiche di contenuto 1n 1007_1 e 1n 1007_2, 2006 (in Italian)

Istat (2011) Spatial data of the 15th general census of population and houses. https://www.istat.it/ it/archivio/104317 (in Italian). Accessed 16 Apr 2019

Klein SA, Beckman WA, Mitchell JW, et al (2014) TRNSYS-A transient system simulation program user manual. The Solar Energy Laboratory-University of Wisconsin, Madison

Ministero dello Sviluppo Economico (MiSE), Ministero dell' Ambiente e della Tutela del Territorio e del Mare (2017) Decreto Ministeriale 10 novembre 2017, Rome (in Italian)

Ministero per la Pubblica Amministrazione e l'Innovazione. Decreto 10 novembre 2011. Regole tecniche per la definizione del contenuto del Repertorio nazionale dei dati territoriali, nonché delle modalità di prima costituzione e di aggiornamento dello stesso (GU n. 48 del 27/02/2012_Suppl. Ordinario n. 37) (in Italian)

MiSE, Ministro dell'Ambiente e della Tutela del Territorio e del Mare, Ministro delle Infrastrutture e dei Trasporti, Ministro per la Semplificazione e la Pubblica Amministrazione, Decreto Ministeriale 26/06/2015. Applicazione delle metodologie di calcolo delle prestazioni energetiche e definizione delle prescrizioni e dei requisiti minimi degli edifici (in Italian)

Pasquinelli A, Guzzetti F (2006) Knowledge for intelligence: discussing the state and the role of building data in Italy. In: International conference on smart data and smart cities, 30th UDMS, Split, Croatia

QGIS Development Team, QGIS Geographic Information System (2019) Open Source Geospatial Foundation Project. http://qgis.osgeo.org. Accessed 16 Apr 2019

Regional energy balance SIRENA20 (2012). http://www.energialombardia.eu/sirena20. Accessed 16 Apr 2019

Repertorio Nazionale dei Dati Territoriali (RNDT). http://geodati.gov.it/geoportale/. Accessed 08 Sep 2018

United Nations (UN) (2015) Transforming our world: the 2030 agenda for sustainable development. Report no. A/RES/70/1, New York

United Nations Environment Programme (UNEP) (2015) District energy in cities-Unlocking the potential of energy efficiency and renewable energy, Nairobi

Zagarella F (2019) Estimating the buildings hourly energy demand for smart energy district planning, Ph.D. thesis, Politecnico di Milano, Milan 
Open Access This chapter is licensed under the terms of the Creative Commons Attribution 4.0 International License (http://creativecommons.org/licenses/by/4.0/), which permits use, sharing, adaptation, distribution and reproduction in any medium or format, as long as you give appropriate credit to the original author(s) and the source, provide a link to the Creative Commons license and indicate if changes were made.

The images or other third party material in this chapter are included in the chapter's Creative Commons license, unless indicated otherwise in a credit line to the material. If material is not included in the chapter's Creative Commons license and your intended use is not permitted by statutory regulation or exceeds the permitted use, you will need to obtain permission directly from the copyright holder.

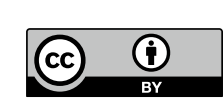

